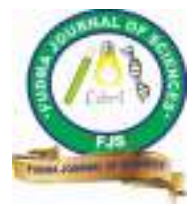

FUDMA Journal of Sciences (FJS)

ISSN online: $2616-1370$

ISSN print: 2645 - 2944

Vol. 4 No. 3, September, 2020, pp 230-241

DOI: https://doi.org/10.33003/fjs-2020-0403-188

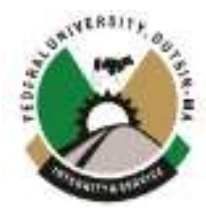

\title{
CO-PRODUCTION OF EXTENDED-SPECTRUM BETA-LACTAMASES AND METALLO BETA-LACTAMASES AMONG MULTI-DRUG RESISTANT GRAM-NEGATIVE BACTERIA ISOLATES COLLECTED FROM TERTIARY HOSPITALS IN OYO STATE, NIGERIA
}

\author{
*1Alabi, O. S., ${ }^{2}$ Obisesan, A. O., ${ }^{1}$ Taiwo, M. K. and ${ }^{1}$ Adewuyi, O. R. \\ ${ }^{* 1}$ Department of Pharmaceutical Microbiology, Faculty of Pharmacy, University of Ibadan, Ibadan, Oyo State, Nigeria. \\ ${ }^{2}$ Department of Pharmacology and Therapeutics, College of Medicine and Health Sciences, Afe-Babalola University, Ado-Ekiti
} (ABUAD), Ekiti State, Nigeria.

*Corresponding Author's E-mail: os.alabi.ui@gmail.com, os.alabi@ui.edu.ng, Phone No.: +2348034740434.

\begin{abstract}
Extended-spectrum beta-lactamases (ESBLs) and metallo beta-lactamases (MBLs) are compromising the chemotherapeutic use of cephalosporins and carbapenems respectively. This study investigated the burden of ESBLs and MBLs co-production among multi-drug resistant (MDR) Gram-negative bacteria collected from two tertiary hospitals in Oyo State. A total of 240 non-duplicated clinical isolates of Escherichia coli, Klebsiella spp. and Pseudomonas spp. were collected from the Microbiology units of two tertiary hospitals in Oyo State and their identities authenticated using standard identification techniques. Antimicrobial susceptibility testing was carried out by disc-diffusion method and isolates exhibiting resistance to $\geq 3$ classes of antibiotics selected as MDR strains. ESBL and MBL production was detected by double-disc synergy test (DDST) and combined-disc-diffusion test (CDDT) respectively. Selected beta-lactamase genes were detected by PCR, amplicons sent out for sequencing and phylogenetic tree of the sequences constructed using Mega X software. MDR was exhibited by $43.8 \%$ of the isolates. ESBLs and MBLs were produced by $32.4 \%$ and $7.6 \%$ of the MDR isolates respectively. Co-production of ESBL and MBL was observed in $6.7 \%$ of the MDR

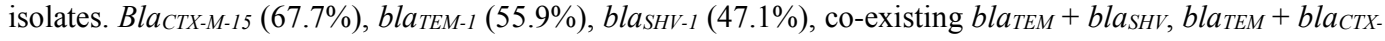
$M$, bla $_{C T X-M}+$ bla $_{S H V}($ each in $5.9 \%)$ and bla $_{C T X-M}+$ bla $_{T E M}+$ bla $_{S H V}(26.5 \%)$ were detected among the ESBLproducers. MBL genes were not detected among the MBL-producers. Only bla different claudes on the phylogenetic tree. The occurrence of MDR isolates co-harbouring different classes of beta-lactamse genes observed in this study is of public health concern and hence, requires stricter control of antibiotic use.
\end{abstract}

Keywords: Extended-spectrum $\beta$-lactamases (ESBLs), metallo- $\beta$-lactamases (MBLs), multidrug resistance (MDR), gramnegative bacteria.

\section{INTRODUCTION}

Antibiotics resistance is a major health problem worldwide with serious impact on cost of care, morbidity, mortality and the length of hospital stay of patients (Carlet et al., 2012, Prestinaci et al., 2015; Founou et al., 2017; Shrestha et al., 2018). The development of antibiotic resistance has been attributed to various factors including selective pressure imposed by use and overuse of antibiotics in human medicine, agriculture and veterinary medicine among others (Hao et al., 2014; Chang et al., 2015; Blaser, 2016). The overuse and misuse of antibiotics in both clinical and community settings has led to the emergence of multi-drug resistance among microorganisms which are occasionally implicated in many infectious outbreaks worldwide (Alabi et al., 2017; Chaw et al., 2018; Chokshi et al., 2019). The lack of frequent monitoring of the use of antibiotics and lack of routine assessments of the potencies and efficacies of the various brands of antimicrobial agents available in the pharmaceutical markets, particularly in developing countries, have led to increase in antibiotic resistance (Lucet et al., 1999; Ayukekbong et al., 2017; Chokshi et al., 2019). In most developing countries like Nigeria, drugs could be brought into the country illegally through the back door without evaluation by relevant regulatory bodies. Some unpatriotic citizens out of the quest to get rich overnight engaged in adulteration and counterfeiting of drugs, particularly antibiotics, and thus exerting a huge impact on the development of antibiotic resistance (Glass, 2014; Kelesidis and Falagas, 2015).

The beta-lactam antibiotics are group of antibiotics widely used in the treatment of infections in both community and clinical settings, and they are divided into narrow, broad and extendedspectrum beta-lactams. While it has been well established that the narrow and some of the broad-spectrum classes of these group of antibiotics are now mostly ineffective clinically due to the emergence of the conventional beta-lactamases (i.e. the class of enzymes that inactivates the narrow spectrum antibiotics), the extended-spectrum beta-lactam antibiotics, such as the third generation cephalosporins (cefotaxime, ceftazidime, ceftriaxone) and the monobactams (aztreonam), developed to overcome the resistance conferred by the conventional beta-lactamases are gradually becoming less effective against most bacterial pathogens due to the advent of superior beta-lactamases known as extended-spectrum betalactamases (ESBLs) that hydrolyses the beta-lactam ring structure of the antibiotics (Alabi et al., 2016). The carbapenems, which were beta-lactam antibiotics of last resort commonly used in the treatment of the extended-spectrum beta-lactamase (ESBL) producing bacteria pathogens are also gradually becoming ineffective against some of these 
pathogens due to the development of a more superior betalactamases generally named carbapenemases part of which are the metallo beta-lactamases (MBLs) (Gaude and Hattiholli, 2013; Worthington and Melander, 2013; Levashov, 2014, Balsalobre et al., 2019, Mirza et al., 2019).

Microbial resistance as a result of ESBL production was first reported in Europe and subsequently in the United States in a single isolate of Klebsiella ozaenae (Bradford, 2001) while MBL was initially reported in a clinical isolate of Serratia marcescens conferring resistance to imipenem (Jiang et al., 2018). Since then, they have emerged in other countries of the world including Nigeria among Gram-negative bacteria particularly the Enterobacteriaceae (Mendonca et al., 2007; Olowe et al., 2012) and Pseudomonas spp. (Oberoi et al., 2013; Kaur and Singh, 2018). Although, the genes coding for these enzymes are mostly borne on resistance plasmids and thus are transferable to other genera or species (Bradford, 2001; Kaur and Singh, 2018; Teklu et al., 2019), some have been reported to be on the chromosome (Mahrouki et al., 2011; Song et al., 2011).

The ESBL enzymes are known to be ineffective against the cephamycin (cefoxitin, cefotetan) and carbapenem (imipenem, meropenem, ertapenem) classes of the beta-lactam antibiotics and hence, the use of carbapenems as the antibiotic of last resort against the ESBL producing bacteria (Teklu et al., 2019). The emergence of the carbapenemases or metallo betalactamases (MBLs) known to hydrolyse the carbapenems and all other beta-lactams, thereby conferring resistance against the antibiotics, is of serious clinical and therapeutic problem (Pitout and Laupland, 2008; Bora et al., 2014; Nepal et al., 2017; Kaur and Singh, 2018).

The scenario of having a microorganism producing different variants of ESBL or MBL and even co-producing both will definitely be of significant public_health concern because of their_effects on the therapeutic options and treatment outcomes. This study ${ }_{2}$ therefore, screened MDR Gram-negative bacteria genera from two selected tertiary hospitals in Oyo state, for the production of ESBLs and MBLs and further determined the occurrence of ESBL and MBL genes among these bacteria isolates.

\section{MATERIALS AND METHODS Ethical Approval}

There was no direct contact or an invasive procedure involved in this study and thus ethical approval is not required. Clinical isolates that are already isolated and characterized from patients that visited the out-patient sections of the teaching hospitals were collected from the microbiology laboratories of the two institutions involved in the study.

\section{Study design and setting}

This was a laboratory-based cross-sectional study involving Microbiology laboratory units of the two tertiary hospitals in Oyo State: University College Hospital (UCH), Ibadan and Ladoke Akintola University of Technology Teaching Hospital (LTH), Ogbomoso, Oyo State, Nigeria. The Gram-negative clinical isolates used in this study were collected using convenient sampling technique from the Microbiology laboratory units of the two tertiary hospitals and the research bench work conducted at the Molecular and Microbiology laboratory of the Department of Pharmaceutical Microbiology, Faculty of Pharmacy, University of Ibadan, Nigeria.

\section{Collection of isolates}

A total of 240 non-duplicated Gram-negative bacteria were collected between September and November, 2018 by convenience sampling on Nutrient agar (Oxoid Ltd, UK) slants at the Microbiology laboratories of University College Hospital (UCH), Ibadan and Ladoke Akintola University of Technology Teaching Hospital (LTH), Ogbomoso, Oyo state, Nigeria and transported to the main laboratory of the Department of Pharmaceutical Microbiology, University of Ibadan within 12 hours of collection for incubation at $37^{\circ} \mathrm{C}$ for 24 hours. From the individual laboratory records, the entire isolates included in this study were from patients who visited the out-patient clinic of the hospitals and the isolates were recovered previously from different specimens such as urine, wound, ear swabs, sputum, catheter tips, pus, semen, aspirate, blood, high vagina swabs, stool, eye swabs and pleural fluid.

\section{Confirmation of the identities of isolates}

After 24 hours of incubation of the isolates collected on slants, they were sub-cultured on different selective media to observe their cultural characteristics and purity. Presumptive $E$ coli collected were sub-cultured on MacConkey and Eosin Methylene Blue Agar (Oxoid Ltd, UK) to observe for the pink and green metallic sheen colonies respectively, characteristic of E coli. Presumptive Pseudomonas spp. were sub-cultured on cetrimide agar which permits the growth of the bacteria only. Presumptive Klebsiella spp. were sub-cultured on MacConkey agar to observe for the pink, mucoid colonies, characteristic of the bacteria. All the streaked plates were incubated in an inverted position for 24 hours at $37^{\circ} \mathrm{C}$. The emergent pure colonies were further subjected to standard biochemical test to confirm their identities. Confirmed isolates were streaked on fresh agar slants, incubated at $37^{\circ} \mathrm{C}$ for 24 hours and kept at $4^{\circ} \mathrm{C}$ for further studies.

\section{Antibiotics susceptibility test}

The confirmed isolates were subjected to antimicrobial susceptibility testing against eleven antibiotics using the discdiffusion method on Mueller-Hinton agar. The selected antibiotics are amoxicillin-clavulanic acid (20/10 $\mu \mathrm{g})$, cefotaxime $(30 \mu \mathrm{g})$, ceftazidime $(30 \mu \mathrm{g})$, cefoxitin $(30 \mu \mathrm{g})$, cefepime $(30 \mu \mathrm{g})$, aztreonam $(30 \mu \mathrm{g})$, gentamicin $(10 \mu \mathrm{g})$, ciprofloxacin $(5 \mu \mathrm{g})$, imipenem $(10 \mu \mathrm{g})$, meropenem $(10 \mu \mathrm{g})$ and ertapenem $(10 \mu \mathrm{g})$. Briefly, an overnight culture of each isolate was suspended in sterile normal saline and the turbidity adjusted to $0.5 \mathrm{McF}$ arland standard by dilution. With the aid of sterile cotton swab, each bacterial suspension was inoculated on the dried-surface of Mueller-Hinton agar plate to form a single cell layer lawn. With the aid of a sterile forcep, each of the antibiotic disc was transferred on the inoculated agar plates at equidistance, allowed to stand on the bench for preincubation diffusion for 1 hour and then incubated in an inverted position for 24 hours at $37^{\circ} \mathrm{C}$. The Clinical Laboratory Standard Institute (CLSI, 2017) breakpoints for interpreting antibiotic susceptibility test results as resistant, intermediate or sensitive was used and isolates that exhibited resistance to three or more classes of antibiotics were selected as multidrug resistant (MDR) isolates (Magiorakos et al., 2011). 


\section{Phenotypic detection of ESBL production}

All isolates that exhibited resistance to all the third generation cephalosporins based on the CLSI breakpoint guideline were screened for ESBL production by double-disc synergy tes (DDST). Briefly, bacterial suspension of overnight culture diluted to $0.5 \mathrm{McF}$ arland standard was inoculated on to the dried-surface of Mueller-Hinton agar plate by surface spreading as described previously above. With the aid of sterile forcep, discs (Oxoid Ltd, UK) of cefotaxime $(30 \mu \mathrm{g})$, ceftazidime $(30 \mu \mathrm{g})$ and cefepime $(30 \mu \mathrm{g})$ were placed at $20 \mathrm{~mm}$ distance centre-to-centre around amoxicillin-clavulanic acid $(20 / 10 \mu \mathrm{g})$ disc, allow for pre-incubation diffusion for 1 hour and then incubated in an inverted position for 24 hours at $37^{\circ} \mathrm{C}$. Isolates that exhibited enhanced susceptibility to one or more of the cephalosporin antibiotics (i.e. enhanced zone of inhibition) were selected as potential producers of ESBL.

\section{Phenotypic detection of MBL production}

Bacterial isolates that exhibited resistance to all or any of the three carbapenem antibiotics used in this study were screened for the production of MBL using the combined-disc-diffusion test (CDDT) method as described by Lee et al.(2003) and Pitout et al. (2005). The CDDT was performed using discs of imipenem $(10 \mu \mathrm{g})$, meropenem $(10 \mu \mathrm{g})$ and ertapenem $(10 \mu \mathrm{g})$ alone and a second set of the discs to which $750 \mu \mathrm{g}$ EDTA has been added to make carbapenem+EDTA combined discs. An increase in the zone diameter of $\geq 7 \mathrm{~mm}$ around any or all of the carbapenem+EDTA discs when compared to that of the carbapenem discs alone was considered positive for $\mathrm{MBL}$ production.

\section{Template DNA extraction}

The DNA of the ESBL- and MBL-producers was extracted by boiling method as described by Mendonca et al (2007). Briefly, pure colonies of the ESBL- and MBL-producer were dispersed each into $500 \mu \mathrm{L}$ of sterile distilled deionized water in an eppendorf tube. The inoculum was vortexed to give homogenous bacterial suspension. The suspension was then centrifuge at $10 \mathrm{RCF}$ for 3 mins and the supernatant was carefully discarded leaving the bacterial suspension. A $100 \mu \mathrm{L}$ of fresh sterile deionized water was added into the bacterial cell pellet and re-suspended by vortexing. A small hole was made on the cap of the eppendorf tube and then boiled at $100^{\circ} \mathrm{C}$ for $15 \mathrm{mins}$. The eppendorf tube was then centrifuged for $5 \mathrm{mins}$ at $10 \mathrm{RCF}$ and $50 \mu \mathrm{L}$ of the supernatant was picked with a sterile micropipette into a new sterile eppendorf tube. The DNA was stored at $-20^{\circ} \mathrm{C}$ for PCR analysis.

\section{PCR detection of ESBL and MBL genes}

For amplification of all the beta-lactamase genes, a reaction volume of $20 \mu \mathrm{L}$ containing $10 \mu \mathrm{L}$ of pre-mixed master mix (Inqaba Biotech, SA), 8 or $7 \mu \mathrm{L}$ of sterile distilled deionized water (for simplex and multiplex reactions respectively), $0.5 \mu \mathrm{L}$ of each of the forward and reverse primers and $1 \mu \mathrm{L}$ of the template DNA was prepared. For bla $a_{\mathrm{CTX}-\mathrm{M}}$ gene (Forward: TTT GCG ATG TGC AGT ACC AGT AA and Reverse: CGA TAT CGT TGG TGG TGC CAT A), conditions for the simplex PCR protocol was 5 minutes at $94^{\circ} \mathrm{C}$ followed by 31 cycles of 1 minute at $94^{\circ} \mathrm{C}, 1 \_$minute at $56^{\circ} \mathrm{C}, 1$ minute at $72^{\circ} \mathrm{C}$ and concluded by 10 minutes at $72^{\circ} \mathrm{C}$. For bla GAGTATTCAACATTTTCGT and Reverse:
ACCAATGCTTAATCAGTGA) and blashv (Forward: TCGCCTGTGTATTATCTCCC and Reverse: CGCAGATAAATCACCACAATG), conditions for the multiplex PCR protocol include $5 \mathrm{~min}$ at $94^{\circ} \mathrm{C}$, followed by 30 cycles of $94^{\circ} \mathrm{C}$ for $30 \mathrm{sec}, 50^{\circ} \mathrm{C}$ for $30 \mathrm{sec}$, and $72^{\circ} \mathrm{C}$ for 1.5 min. For bla $a_{\mathrm{NDM}-1}$ gene (Forward: GGTTTGGCGATCTGGTTTTC, Reverse: CGGAATGGCTCATCACGATC), the PCR conditions was 10 min at $94^{\circ} \mathrm{C} ; 36$ cycles of amplification consisting of $30 \mathrm{sec}$ at $94^{\circ} \mathrm{C}, 40 \mathrm{sec}$ at $52^{\circ} \mathrm{C}$, and $50 \mathrm{sec}$ at $72^{\circ} \mathrm{C}$; and $5 \mathrm{~min}$ at $72^{\circ} \mathrm{C}$ for the final extension. For bla $a_{\mathrm{IMP}}$ (Forward: TTTCATATGGCAGAGTCTTTGCCAGATT, Reverse: ATCCTAGAAATTTAGTTGCTTGGTT) and blaviM (Forward: ATGTTCAAACTTTTGAGTAAG, Reverse: CTACTCAACGACTGAGCG), multiplex PCR conditions include $95^{\circ} \mathrm{C}$ for $5 \mathrm{~min}$, followed by 30 cycles at $95^{\circ} \mathrm{C}$ for 1 min, annealing at $45^{\circ} \mathrm{C}$ for $1 \mathrm{~min}$, an extension at $68^{\circ} \mathrm{C}$ for 1 min, ending with incubation for $5 \mathrm{~min}$ at $68^{\circ} \mathrm{C}$. For bla $\mathrm{KPC}$ gene (Forward: ATGTCACTGTATCGCCGTC, Reverse: CTCAGTGCTCTACAGAAAACC), the PCR conditions include $5 \mathrm{~min}$ at $95^{\circ} \mathrm{C}$, followed by 35 cycles of denaturation at $95^{\circ} \mathrm{C}$ for $1 \mathrm{~min}$, annealing at $58^{\circ} \mathrm{C}$ for $30 \mathrm{sec}$, extension at $72^{\circ} \mathrm{C}$ for $1 \mathrm{~min} 30 \mathrm{sec}$ and final extension at $72^{\circ} \mathrm{C}$ for $10 \mathrm{~min}$. The PCR products were visualized on $1.5 \%$ Agarose gel stained with $\mathrm{EZ}$ vision and visualized with $\mathrm{UVP}{ }^{\circledR}$ GelMax ${ }^{\circledR}$ UV Gel Imager. The expected amplicon sizes of bla $a_{\mathrm{TEM}}$, bla $_{\mathrm{SHV}}$, bla $_{\mathrm{CTX}}$ M, bla $a_{\mathrm{NDM}-1}$, bla VIM $_{1}$ bla $a_{\mathrm{IMP}}$ and bla $a_{\mathrm{KPC}}$ are $857,768,543,621$, 741,801 and 872 bp respectively. The amplicons were sent out to Inqaba Biotechnology Laboratory, South Africa, for sequencing. Three sequences each, of bla TEM-I $_{\text {(Accession Nos.: }}$ MT636821.1; MT636815.1 \& NG050145.1), blashV-1 (Accession Nos.: MK482385.1; MK099071.1 \& FJ668802.1) and bla $a_{T X-M-15}$ (Accession Nos.: KY640567; KY640574.1 \& NG048935.1) genes were selectively downloaded from genbank on NCBI website and combined with the sequences of the amplicons from this study to construct a phylogenetic tree by the neighbor-joining method to compare the sequences using the Molecular Evolutionary Genetics Analysis (MEGA) X software version 10.0.4.

\section{RESULTS}

Out of the 240 isolates collected, $24.2 \%$ (58/240) were from Ladoke Akintola University of Technology teaching hospital (LTH) while $75.8 \%$ (182/240) were from University College Hospital (UCH). The isolates were recovered from urine (32.9\%), wounds $(20.8 \%)$, ear swabs $(11.3 \%)$, sputum $(8.3 \%)$, catheter tips $(4.6 \%)$, pus $(4.2 \%)$, semen $(3.8 \%)$, aspirate (3.3\%), blood (2.9\%), vagina swabs $(2.5 \%)$, stool (2.5\%), eye swabs $(1.7 \%)$ and pleural fluid $(1.3 \%)$ with higher percentage of each of the bacterial specie collected from $\mathrm{UCH}$ as presented in table 1.

Excluding cefotaxime, cefoxitin and ertapenem against Pseudomonas spp., the results of the antibiotic susceptibility test showed that $73.8 \%$ of the isolates were resistant to amoxicillin-clavulanic acid, $58.8 \%$ to gentamicin, $49.6 \%$ to cefotaxime, $48.8 \%$ to aztreonam, $47.9 \%$ to ciprofloxacin and $45.4 \%$ to ceftazidime. Resistances to imipenem, meropenem and ertapenem were exhibited by $14.2 \%, 8.3 \%$ and $7.9 \%$ of the isolates (Table 2) In this study, $43.8 \%$ of the isolates exhibited MDR phenotype cumulatively. including $28.8 \%$, $53.8 \%$ and $48.8 \%$ of the Pseudomonas spp., Klebsiella spp. and 
E. coli isolates respectively (Figure 1). ESBL production was detected in $32.4 \%$ of the MDR isolates cumulatively, including $33.3 \%, 44.2 \%$ and $8.7 \%$ of the E coli, Klebsiella spp. and Pseudomonas spp. resistant to the cephalosporins respectively. Production of MBL was detected in $7.6 \%$ of the MDR isolates cumulatively, including $7.7 \%, 4.7 \%$ and $13 \%$ of the $E$ coli, Klebsiella spp. and Pseudomonas spp. resistant to the carbapenems (Figure 2). Co-production of ESBL and MBL was observed phenotypically in $6.7 \%$ of the MDR isolates (Figure 3). The PCR screening for the presence of ESBL and MBL genes detected $67.7 \%$ of the isolates harbouring bla $a_{\text {CTX-M, }}$ $55.9 \%$ harbouring bla the ESBL producers. Relatively among each of the genera, $50 \%$ of the ESBL producing Pseudomonas spp. harboured bla

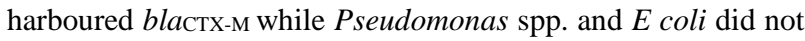
harbour bla $a_{\mathrm{SHV}}$ (Figure 4). Co-existence of blateM +blashv, blaTEM+blaCTX-M and blactX-M+blasHV was detected in $5.9 \%$ of the ESBL producers in each case while $26.5 \%$ co-harboured blaTEM+blasHV+bla $a_{C T X-M}$ genes. Coexistence of bla $a_{T E M}+b l a_{S H V}$, blactX-M+blatem and blactX-M+blashV was detected each in
$10.5 \%$ of the ESBL producing Klebsiella spp. while blatEM+blasHV+blactX-M coexisted in $31.6 \%$ and $23.1 \%$ of ESBL producing Klebsiella spp. and $E$ coli respectively (Figure 4). The ESBL genes and MBL enzymes detected in this study are harboured by isolates mostly from urine $(37.1 \%)$, wound $(31.4 \%)$, catheter tip (8.6\%), stool (5.7\%), sputum $(5.7 \%)$, aspirate $(5.7 \%)$, HVS $(2.9 \%)$ and blood $(2.9 \%)$ (Table 3). Analysis of the amplicons' sequences on National Center for Biotechnology Information (NCBI) BLAST website identified bla $a_{\mathrm{TEM}}$ as bla $a_{\mathrm{TEM}-1}$, bla $_{\mathrm{SHV}}$ as bla $a_{\mathrm{SHV}-1}$ and bla $_{\mathrm{CTX}-\mathrm{M}}$ as

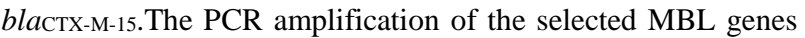
(bla $a_{\mathrm{IMP}}, b l a_{\mathrm{VIM}}, b l a_{\mathrm{NDM}-1}$ and $\left.b a_{\mathrm{KPC}}\right)$ did not give amplicons. The phylogenetic tree reflected close relationship in the sequences of each type of the ESBL genes sequenced and those downloaded from genbank on the NCBI website. However, for the bla ${ }_{T E M-1}$ genes, out of the 19 sequences, 5 (26.3\%) showed closed similarities with the three downloaded blaTEM-1 sequences while $14(73.7 \%)$ showed closed similarities but with some level of differences from the downloaded and the five sequences as shown in figure 5 .

Table 1: Distribution of isolates among the two tertiary hospitals and specimen types

\begin{tabular}{|c|c|c|c|c|c|}
\hline & \multirow{2}{*}{ Variables } & \multirow{2}{*}{$\begin{array}{c}\mathrm{N} / \% \\
(\mathrm{~N}=240)\end{array}$} & \multicolumn{3}{|c|}{ Distribution (n/\%) by hospitals and specimens } \\
\hline & & & Pseudomonas spp. & Klebsiella spp. & Escherichia coli \\
\hline \multirow[t]{3}{*}{ Hospital } & LTH & $58(24.2)$ & $12(20.6)$ & $23(39.7)$ & $23(39.7)$ \\
\hline & $\mathrm{UCH}$ & $182(75.8)$ & $68(37.4)$ & $57(31.3)$ & $57(31.3)$ \\
\hline & Total (N/\%) & $240(100.0)$ & $80(33.3)$ & $80(33.3)$ & $80(33.3)$ \\
\hline \multirow{13}{*}{ Specimen } & Urine & 79 (32.9) & $19(24.1)$ & $16(20.3)$ & $44(55.6)$ \\
\hline & Wound swab & $50(20.8)$ & $19(38)$ & $21(42)$ & $10(20)$ \\
\hline & Ear swab & $27(11.3)$ & $23(85.2)$ & $3(11.1)$ & $1(3.7)$ \\
\hline & Sputum & $20(8.3)$ & $0(0)$ & $20(100)$ & $0(0)$ \\
\hline & Catheter tip & $11(4.6)$ & $8(72.7)$ & $1(9.1)$ & $2(18.2)$ \\
\hline & Pus & $10(4.2)$ & $0(0)$ & $4(40)$ & $6(60)$ \\
\hline & Semen & $9(3.8)$ & $2(22.2)$ & $3(33.3)$ & $4(44.4)$ \\
\hline & Aspirate & $8(3.3)$ & $1(12.5)$ & $5(62.5)$ & $2(25)$ \\
\hline & Blood & $7(2.9)$ & $3(42.8)$ & $2(28.6)$ & $2(28.6)$ \\
\hline & HVS & $6(2.5)$ & $2(33.3)$ & $2(33.3)$ & $2(33.3)$ \\
\hline & Stool & $6(2.5)$ & $0(0)$ & $0(0)$ & $6(100)$ \\
\hline & Eye swab & $4(1.7)$ & $2(50)$ & $2(50)$ & $0(0)$ \\
\hline & Pleural fluid & $3(1.3)$ & $1(33.3)$ & $1(33.3)$ & $1(33.3)$ \\
\hline
\end{tabular}

Legend: LTH - Ladoke Akintola University of Technology Teaching Hospital; UCH - University College Hospital 
Table 2: The percentage resistance pattern of the clinical isolates against selected antibiotics

\begin{tabular}{|c|c|c|c|c|}
\hline \multirow{2}{*}{ Antibiotics } & \multicolumn{4}{|c|}{ Resistance pattern (n/\%) } \\
\hline & $\begin{array}{l}\text { Pseudomonas spp. } \\
(\mathrm{n}=80)\end{array}$ & $\begin{array}{l}\text { Klebsiella spp. } \\
\quad(\mathrm{n}=80)\end{array}$ & $\begin{array}{l}\text { Escherichia coli } \\
(\mathrm{n}=80)\end{array}$ & $\begin{array}{l}\text { Total Resistance } \\
\quad(\mathrm{N}=240)\end{array}$ \\
\hline $\begin{array}{l}\text { Amoxicillin-clavulanic acid (AMC) } \\
-20 / 10 \mu \mathrm{g}\end{array}$ & $79(98.8)$ & $34(42.5)$ & $36(45)$ & $177(73.8)$ \\
\hline Cefotaxime (CTX)- 30 $\mathrm{gg}$ & ND & $63(78.8)$ & $55(68.8)$ & $119(49.6)$ \\
\hline Ceftazidime (CAZ) - 30 $\mathrm{g}$ & $10(12.5)$ & $56(70)$ & $41(51.3)$ & $109(45.4)$ \\
\hline 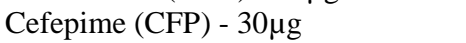 & $13(16.3)$ & $42(52.2)$ & $35(43.8)$ & $90(37.5)$ \\
\hline Cefoxitin (FOX) - 30 $\mu \mathrm{g}$ & ND & $34(42.5)$ & $22(27.5)$ & $56(23.3)$ \\
\hline 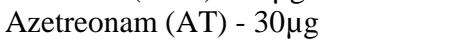 & $12(15)$ & $58(72.5)$ & $44(55)$ & $117(48.8)$ \\
\hline Gentamicin $(\mathrm{GN})-10 \mu \mathrm{g}$ & $46(57.5)$ & $63(78.8)$ & $43(53.8)$ & $141(58.8)$ \\
\hline 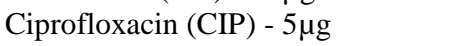 & $26(32.5)$ & $51(63.8)$ & $47(58.8)$ & $115(47.9)$ \\
\hline 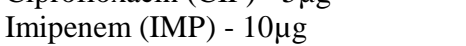 & $8(10)$ & $13(16.3)$ & $15(18.8)$ & $34(14.2)$ \\
\hline Meropenem (MEM) - 10 $\mu \mathrm{g}$ & $5(6.3)$ & $6(7.5)$ & $9(11.3)$ & $20(8.3)$ \\
\hline 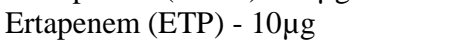 & ND & $7(8.8)$ & $12(15)$ & $19(7.9)$ \\
\hline
\end{tabular}

Legend: ND: Not Done

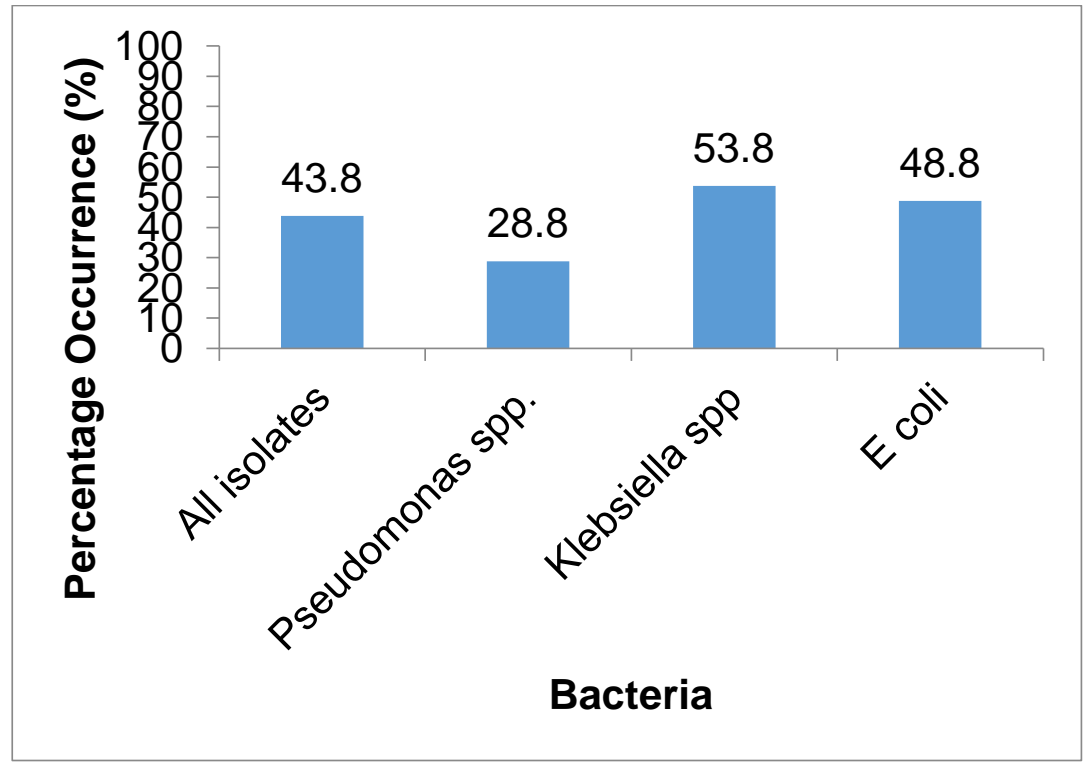

Figure 1: Percentage distribution of MDR phenotype among the isolates 


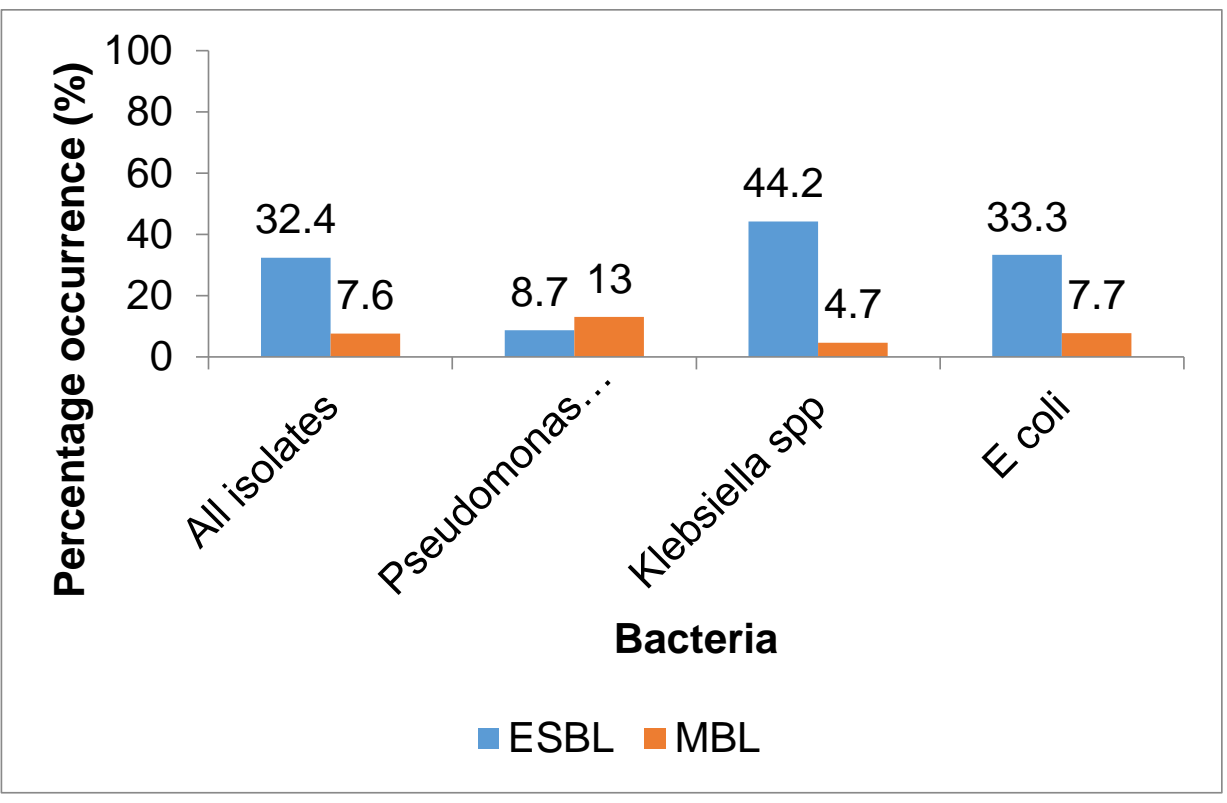

Figure 2: Percentage distribution of ESBL and MBL producers among the MDR isolates

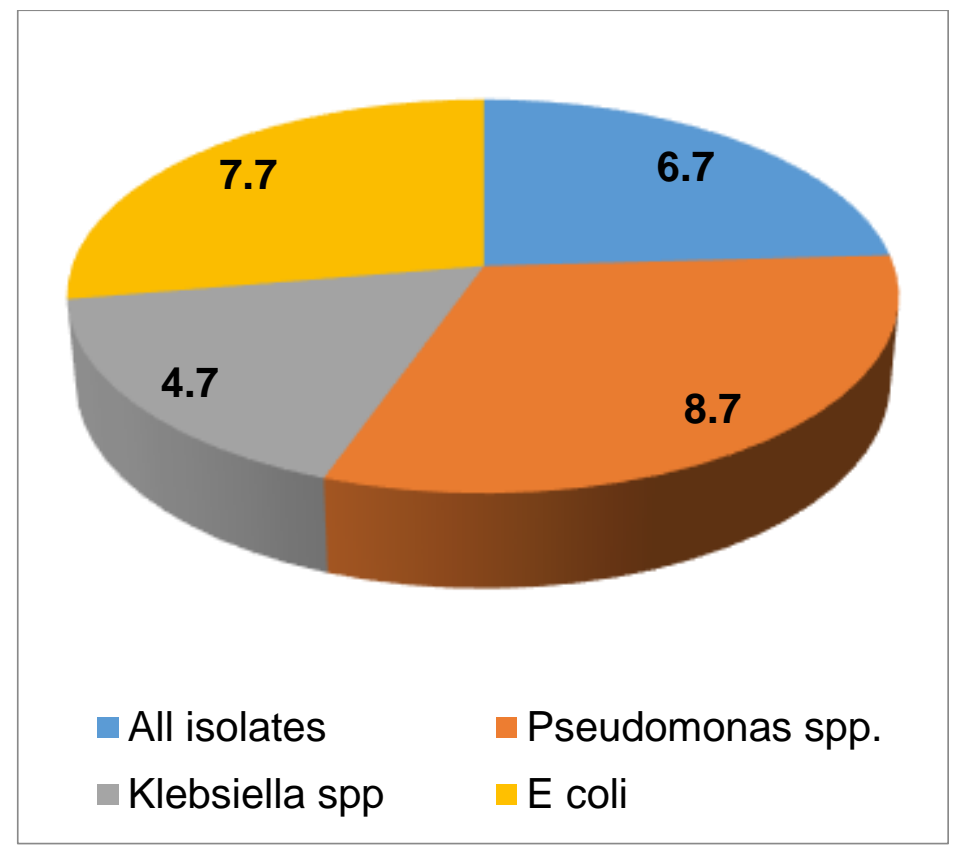

Figure 3: Percentage distribution of co-producers of ESBL and MBL among the MDR isolates 


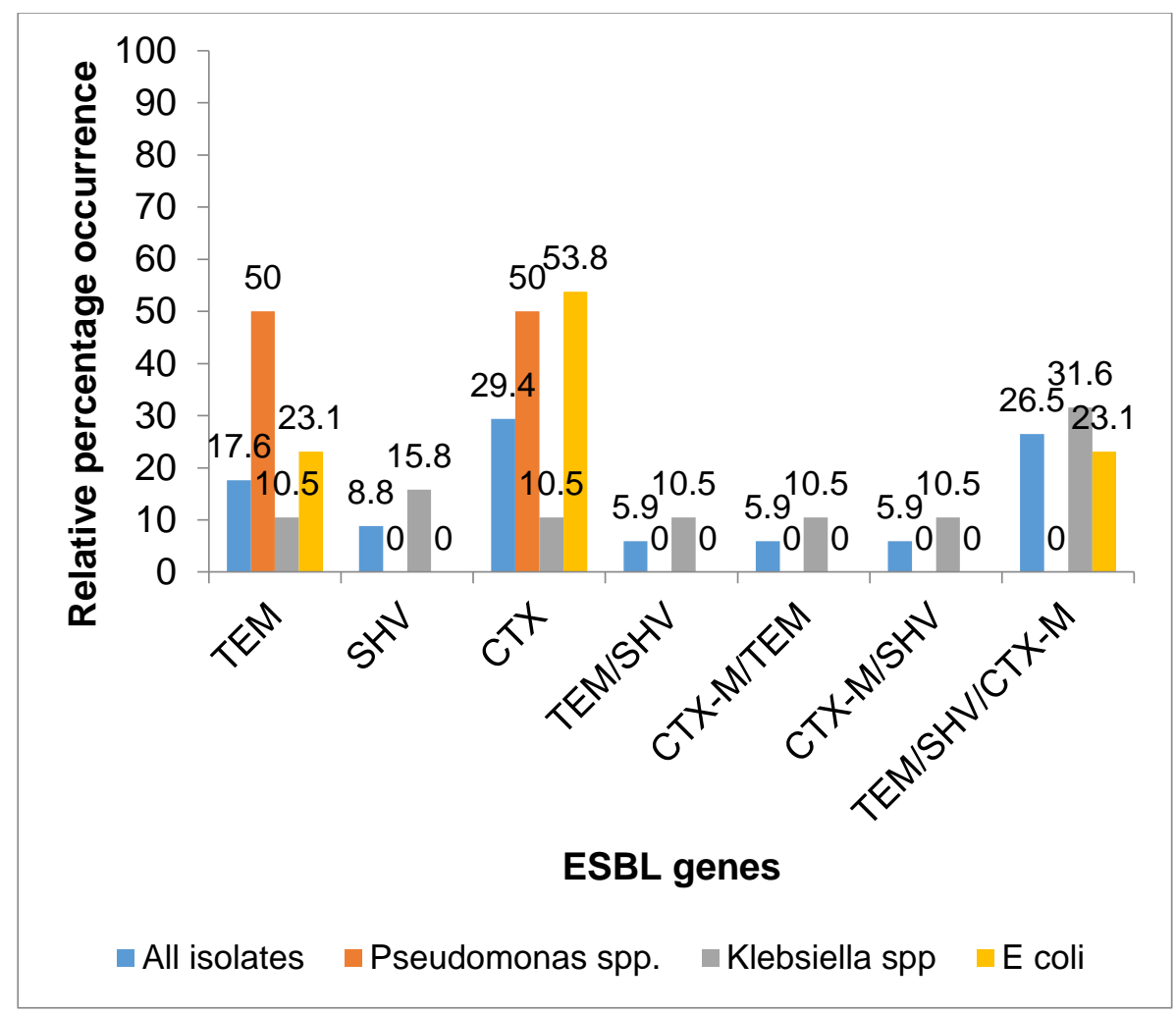

Figure 4: Relative percentage distribution of ESBL genes among the producing isolates 
Table 3: Distribution of MDR, ESBL, MBL phenotypes and the beta-lactamase genes among the clinical isolates and the specimens in the two tertiary hospitals

\begin{tabular}{|c|c|c|c|c|c|c|}
\hline \multirow{2}{*}{ Isolate ID } & \multirow{2}{*}{ Hosp. } & \multirow{2}{*}{ Sample } & \multicolumn{3}{|c|}{ Phenotypes } & \multirow{2}{*}{$\begin{array}{c}\text { Genotypes } \\
\text { Genes }\end{array}$} \\
\hline & & & MDR & ESBL & MBL & \\
\hline EC008 & LTH & Urine & + & + & - & TEM \\
\hline EC009 & LTH & Wound & + & + & - & CTX-M \\
\hline EC012 & LTH & Urine & + & + & - & TEM,SHV,CTX-M \\
\hline EC200 & LTH & Urine & + & + & - & CTX-M \\
\hline EC030 & LTH & Wound & + & + & - & CTX-M \\
\hline EC033 & $\mathrm{UCH}$ & Urine & + & + & + & TEM,SHV, CTX-M \\
\hline EC046 & $\mathrm{UCH}$ & Urine & + & + & + & TEM,SHV,CTX-M \\
\hline EC057 & $\mathrm{UCH}$ & HVS & + & + & - & CTX-M \\
\hline EC064 & $\mathrm{UCH}$ & Wound & + & + & + & CTX-M \\
\hline EC080 & $\mathrm{UCH}$ & Urine & + & + & - & TEM \\
\hline EC084 & $\mathrm{UCH}$ & Stool & + & + & - & CTX-M \\
\hline EC467 & $\mathrm{UCH}$ & Wound & + & + & - & CTX-M \\
\hline EC963 & $\mathrm{UCH}$ & Urine & + & + & - & TEM \\
\hline KL005 & LTH & Sputum & + & + & - & CTX-M \\
\hline KL120 & LTH & Aspirate & + & + & - & SHV \\
\hline KL012 & LTH & Stool & + & + & - & CTX-M \\
\hline KL140 & LTH & Urine & + & + & + & TEM,SHV,CTX-M \\
\hline KL200 & LTH & Wound & + & + & - & TEM \\
\hline KL022 & LTH & Wound & + & + & - & SHV \\
\hline KL250 & LTH & Aspirate & + & + & - & TEM \\
\hline KL025 & LTH & Blood & + & + & - & TEM,SHV,CTX-M \\
\hline KL077 & $\mathrm{UCH}$ & Urine & + & + & - & TEM,SHV,CTX-M \\
\hline KL081 & $\mathrm{UCH}$ & Sputum & + & + & + & SHV,CTX-M \\
\hline KL433 & $\mathrm{UCH}$ & Wound & + & + & - & SHV \\
\hline KL435 & $\mathrm{UCH}$ & Urine & + & + & - & TEM,SHV,CTX-M \\
\hline KL698 & $\mathrm{UCH}$ & Urine & + & + & - & TEM,SHV,CTX-M \\
\hline KL786 & $\mathrm{UCH}$ & Catheter tip & + & + & - & TEM,SHV,CTX-M \\
\hline KL860 & $\mathrm{UCH}$ & Wound & + & + & - & TEM,SHV \\
\hline KL887 & $\mathrm{UCH}$ & Catheter tip & + & + & - & TEM, CTX-M \\
\hline KL889 & $\mathrm{UCH}$ & Wound & + & + & - & TEM,CTX-M \\
\hline KL914 & $\mathrm{UCH}$ & Wound & + & + & - & SHV,CTX-M \\
\hline KL926 & $\mathrm{UCH}$ & Urine & + & + & - & TEM,SHV \\
\hline PS088 & LTH & Wound & + & + & + & TEM \\
\hline PS918 & $\mathrm{UCH}$ & Urine & + & + & + & CTX-M \\
\hline PS436 & $\mathrm{UCH}$ & Catheter tip & + & - & + & - \\
\hline
\end{tabular}




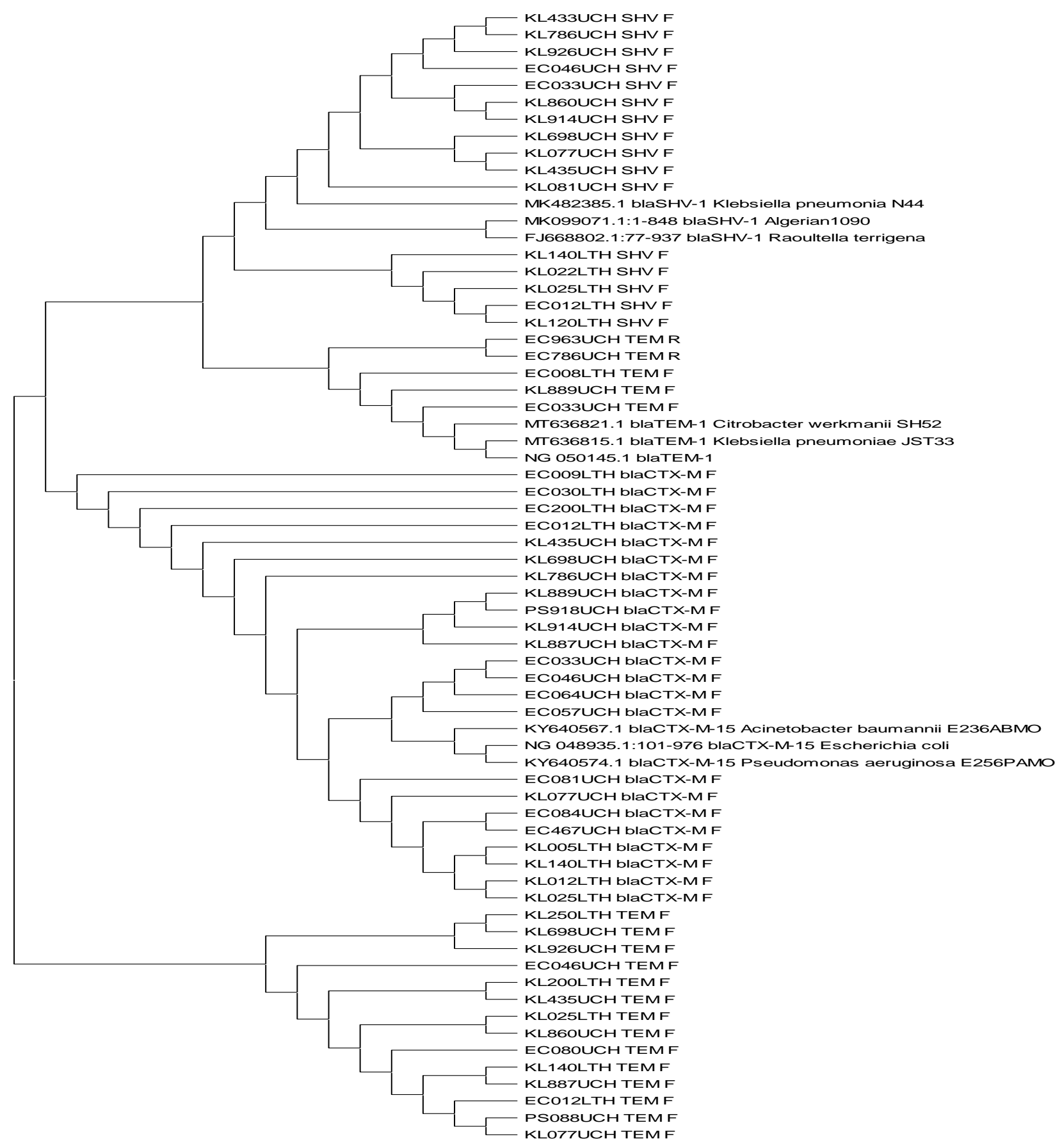

Figure 5: Phylogenetic tree showing evolutionary relationships of the ESBL sequences

\section{DISCUSSION}

Gram-negative bacteria exhibiting multiple resistance to several classes of antibiotic are on the increase and cut across almost all genera and species, most especially among the Enterobacteriaceae and Pseudomonadaceae (Leverstein-van Hall et al., 2003; Lynch III et al., 2013; Yadav et al., 2015; Cilloniz et al., 2019). The ability of the individual microorganism toacquire resistance determinants through mobile genetic elements and transfer the resistance traits among themselves coupled with the principle of selective pressure as a result of misuse or overuse of broad and extended-spectrum antibiotics have encouraged the spread of multiple antibiotic resistance among these microorganisms (Thanner et al., 2016; Manyi-Loh et al., 2018). The increase in the use of beta-lactam antibiotics, particularly the broad and extendedspectrum beta-lactams in both community and clinical infectious cases have partly contributed to the high prevalence of ESBL and MBL producing bacteria causing infections worldwide (Rawat and Nair, 2010; Teklu et al., 2019). In this study, three most commonly encountered bacteria genera in most infectious cases were selected for collection and the highest percentage were recovered from urine $(32.9 \%)$, most especially $E$ coli $(55.6 \%)$. This is not surprising as Enterobacteriaceae in particular, are part of the leading causes of urinary tract infection (UTI), particularly among 
female subjects due to the proximity of their anus to the urinary tract compared to the male subjects (Behzadi et al., 2010).

In this study, higher percentage of the isolates exhibited resistance to amoxicillin-clavulanic acid $(73.8 \%)$ and gentamicin $(58.8 \%)$ while lower resistance was observed against imipenem (14.2\%), meropenem (8.3\%) and ertapenem (7.9). This result was relatively similar to that described by Teklu et al. (2019) where $71.6 \%$ of the isolates exhibited resistance against amoxicillin-clavulanic acid, 43.4\% against gentamicin and 5.2\% against meropenem. However, Olowookere et al (2019), in a study carried out on Gram-negative bacteria isolates in a hospital in the Northwest of Nigeria reported lower level of resistance to amoxicillin-clavulanic acid (45.7\%) and gentamicin $(38.8 \%)$ but higher level of resistance to carbapenems (28.2\%).Considering each of the genera, it was observed in this study that higher percentage of the Klebsiella spp. exhibited resistance against cefotaxime $(78.8 \%)$, gentamicin $(78.8 \%)$, ceftazidime $(70 \%)$ and aztreonam $(72.5 \%)$ while lower percentage exhibited resistance against meropenem $(7.5 \%)$, Ertapenem $(8.8 \%)$ and imipenem $(16.3 \%)$ compared to the other genera. High percentage of the $E$ coliisolates exhibited resistance mainly to cefotaxime $(68.8 \%)$ with moderate percentage resistance against other antibiotics. However, higher percentage of $E$ coli relatively exhibited resistance to meropenem (11.3\%), ertapenem (15\%) and imipenem (18.8\%) compared to Klebsiella spp. in this study. Teklu et al. (2019) reported slightly similar antibiotic susceptibility profile against the Klebsiella pneumoniae isolates where $86.4 \%$ of the isolates were resistant to cefotaxime, $85.4 \%$ to ceftazidime, $70 \%$ to gentamicin and $10.7 \%$ to meropenem. However, contrary to this study, $23.3 \%$ of the Klebsiella pneumoniae isolates from the work of Teklu et al. (2019) were resistant to aztreonam as against $72.5 \%$ in this study. Also, $3.5 \%$ of the $E$ coli isolates from the work of Teklu et al. (2019) were resistant to meropenem as against $11.3 \%$ resistance in this study. The Pseudomonas spp. isolates in this study exhibited highest percentage resistance against amoxicillin-clavulanic acid (98.8\%) but lowest percentage resistance to the other antibiotics such as ceftazidime $(12.5 \%)$, cefepime $(16.3 \%)$, aztreonam $(15 \%)$, ciprofloxacin $(32.5 \%)$, imipenem $(10 \%)$ and meropenem $(6.3 \%)$ compared to the two other genera. However, Kaur and Singh (2018) gave a contrary report where the Pseudomonas aeruginosa isolated from different specimens from patients in intensive care unit (ICU) in Bathinda, India exhibited higher percentage resistance against ceftazidime (60.9\%), cefepime (57.8\%), aztreonam $(55.2 \%)$, gentamicin $(44.3 \%)$, ciprofloxacin $(42.8 \%)$, meropenem (35.5\%) and imipenem (28.6\%) compared to the Pseudomonas spp. from this study. Higher percentage of the isolates in this study exhibited MDR (43.8\%) phenotypes. When considering the individual genera, relatively, higher percentage of the Klebsiella spp. exhibited MDR phenotype (53.8\%) compared to the two other genera. This scenario was also reported by Teklu et al. (2019) where among the 103 Klebsiella pneumoniae isolates collected $82.5 \%$ of them were MDR compared to the other genera among the426 isolates. Ugwu et al. (2020) in a study carried out on uropathogens in Southeastern Nigeria also reported Klebsiella spp. recording the highest MDR phenotype among the other clinical isolates. Olowookere et al (2019) reported lower (26\%) MDR phenotype among the Gram-negative bacteria isolates from a hospital in the Northwest of Nigeria. Phenotypically, low level ESBL (32.4\%) and MBL (7.6\%) producers was recorded in this study with relatively, higher percentage of the Klebsiella spp. (44.2\%) producing ESBL compared to the E coli (33.3\%), and lesser percentage producing MBL (4.7\%) compared to the $E$ coli (7.7\%). This was partly similar to the report of Ugwu et al. (2020) where phenotypically, $32.0 \%$ and $3.1 \%$ of the entire isolates produced ESBL and MBL respectively but with $E$ coli producing higher percentage of both ESBL (27.6\%) and MBL (5.2\%) compared to the other isolates. However, Olowookere et al (2019) reported higher $(38.0 \%$ ) occurrence of MBL producers among the carbapenem resistance clinical Gram-negative bacteria from Northwest Nigeria with Klebsiella spp. (36.8\%) being the highest producers compared to the other genera. Co-production of both ESBL and MBL was recorded in $6.7 \%$ of the isolates in this study which was highest among the Pseudomonas spp. (8.7\%), followed by the E coli $(7.7 \%)$ and then the Klebsiella spp. (4.7\%). Coexistence of two beta-lactamase genes was recorded only in $5.9 \%$ of the Klebsiella spp. in this study with $31.6 \%$ of the Klebsiella spp. and $23.1 \%$ of the $E$ coli isolates harbouring the three selected ESBL genes $\left(\right.$ bla $a_{\mathrm{TEM}}+b_{\text {bla }}+a_{\mathrm{SHV}}+$ bla $\left._{\mathrm{CTX}-\mathrm{M}}\right)$. Similar scenario was also reported by Ugwu et al. (2020) among clinical isolates of Klebsiella pneumoniae and E coli from Southeastern Nigeria. Coexistence of blaTEM+blasHV+blaoXA-Like genes was recorded among the Klebsiella spp. $(21.4 \%)$ but only bla $a_{T E M}+$ bla $_{S H V}$ was recorded among the E coli $(5.2 \%)$ by Ugwu et al. (2020). In this study, isolates producing MBL was detected but PCR amplification of the target MBL genes did not produced amplicons. This suggests that the isolates are probably resisting the carbapenems via different mechanisms, or possibly, the types of MBL genes harboured by the isolates are different from the specific MBL genes targeted in this study. This however, requires further screening of the isolates for more of the MBL genes by PCR technique or to carry out whole genome sequencing and analysis of the MBL-producers so as to elucidate the exert mechanism(s) of resistance to the carbapenems. The evolutionary relationships expressed by the phylogenetic tree in this study revealed close relationship among all the blasHV-1 genes and among the bla $a_{C T X-M-15}$ genes sequenced with their respective downloaded sequences. However, some level of evolutionary differences was observed among the blaTEM-I sequences. While $5(26.3 \%)$ of the bla to the three downloaded sequences, $14(73.7 \%)$ had relatively different gene sequences compared with the downloaded and the five sequenced genes.

\section{CONCLUSION}

This study reveals the presence of MDR bacteria isolates from community acquired infections co-harbouring multiple types of ESBL genes and co-producing ESBLs and MBLs. This signified a serious public health threat, especially for the carbapenem resistance and thus required continuous surveillance and strict restrictions in the use of extended-spectrum beta-lactams and carbapenems for community based infections to prevent further increases and spread within the community.

\section{ACKNOWLEDGEMENT}

The authors acknowledged the Head of the Molecular Laboratory of the Department of Pharmaceutical Microbiology, Faculty of Pharmacy, University of Ibadan, Professor Iruka N. Okeke, for her permission to carry out the molecular aspect of this research in her laboratory and for providing some vital materials such as Agarose gel, electrophoresis and PCR apparatus used in this study.

\section{REFERENCES}

Alabi, O. S.,Mendonça, N., Adeleke, O. E. and da Silva, G. J. (2017).Molecular screening of antibiotic-resistant determinants among multidrug-resistant clinical isolates of Proteus mirabilis from southwest Nigeria. African Health Sciences. 17(2): 356-365.

Alabi, O. S.,Obisesan,A. O. and Ola,A. A. (2016). Prevalence of methicillin-resistant Staphylococcus aureus and extendedspectrum $\beta$-lactamase producers among bacteria isolated from infected wounds in a tertiary hospital in Ibadan city. African Journal of Clinical and Experimental Microbiology. 17(4):235242. 
Ayukekbong, J. A., Ntemgwa, M. and Atabe, A. N. (2017). The threat of antimicrobial resistance in developing countries: causes and control strategies. Antimicrobial Resistance and Infection Control.6(1):47.

Balsalobre, L., Blanco, A. and Alarcón, T. (2019). Beta- Lactams. Antibiotic Drug Resistance, 57-72. Available at: https://doi.org/10.1002/9781119282549.ch3.

Behzadi, P., Behzadi, E., Yazdanbod, H., Aghapour, R., Akbari, C. M. and Salehian, O. D. (2010). A survey on urinary tract infections associated with the threemost common uropathogenic bacteria Maedica (Buchar).5(2):111-115.

Blaser, M. J. (2016). Antibiotic use and its consequences for the normal microbiome. doi:10.1126/science.aad9358

Bora, A., Sanjana, R., Jha, B. K., Mahaseth, S. N. and Pokharel, K. (2014). Incidence of metallo-beta-lactamase producing clinical isolates of Escherichia coli and Klebsiella pneumoniae in central Nepal. BMC Res Notes.7:557.

Bradford, P. A. (2001). Extended-spectrum $\beta$-lactamases in the 21st century: characterization, epidemiology, and detection of this important resistance threat. Clinical microbiology reviews, 14(4), 933-951.

Carlet, J., Jarlier, V., Harbarth, S., Voss, A., Goossens, H. and Pittet, D. (2012). Ready for a world without antibiotics? The pensières antibiotic resistance call to action:Antimicrobial and Infection Control. $\quad 1: 11$ Available at:http://www.aricjournal.com/content/1/1/11

Chang, Q., Wang, W., Regev-Yochay, G., Lipsitch, M. and Hanage, W. P. (2015). Antibiotics in agriculture and the risk to human health: how worried should we be?Evol Appl.8(3):240-247. doi:10.1111/eva.12185

Chaw, P. S., Höpner, J. and Mikolajczyk, R. (2018). The knowledge, attitude and practice of health practitioners towards antibiotic prescribing and resistance in developing countries-A systematic review. J Clin Pharm Ther. 43(5):606-613. doi: $10.1111 /$ jcpt.12730

Chokshi, A., Sifri, Z., Cennimo, D. and Horng, H. (2019). Global Contributors to Antibiotic Resistance. J Glob Infect Dis. 11(1):3642. doi:10.4103/jgid.jgid_110_18

Cilloniz, C., Dominedo, C. and Torres, A. (2019). Multidrug Resistant Gram-Negative Bacteria in Community-Acquired Pneumonia. Crit Care23: 79. https://doi.org/10.1186/s13054-0192371-3

Clinical and Laboratory Standards Institute, (2017). Performance Standards for Antimicrobial Susceptibility Testing; Eighteenth Informational Supplement M100-S27, Clinical and LaboratoryStandards Institute, Wayne, PA, USA.

Founou, R. C., Founou, L. L. and Essack, S. Y. (2017). Clinical and economic impact of antibiotic resistance in developing countries: a systematic review and meta-analysis. PLOS One.12:e189621. doi:10.1371/journal.pone.0189621

Gaude, G. S. and Hattiholli, J. (2013). Rising bacterial resistance to beta-lactam antibiotics: Can there be solutions? Journal of $\mathrm{Dr}$. NTR University of Health Sciences, 2(1):4.
Glass, B. D. (2014). Counterfeit drugs and medical devices in developing countries. Research and Reports in Tropical Medicine, 2014: $11-22$

Hao, H., Cheng, G., Iqbal, Z., Ai, X., Hussain, H. I., Huang, L., Dai, M., Wang, Y., Liu, Z. and Yuan, Z. (2014). Benefits and risks of antimicrobial use in food-producing animals. Front Microbiol.5:288. doi:10.3389/fmicb.2014.00288

Jiang, X. W., Cheng, H., Huo, Y. Y., Xu, L., Wu, Y. H., Liu, W. H., Tao, F. F., Cui, X. J. and Zheng, B. W. (2018). Biochemical and genetic characterization of a novel metallo- $\beta$-lactamase from marine bacterium Erythrobacter litoralis HTCC 2594. Scientific reports, 8(1), 803.doi: 10.1038/s41598-018-19279-0.

Kaur, A. and Singh, S. (2018). Prevalence of extended spectrum betalactamase (ESBL) and metallobetalactamase (MBL) producing Pseudomonas aeruginosa and Acinetobacter baumannii isolated from various clinical samples. Journal of pathogens.2018: 1 7.https://doi.org/10.1155/2018/6845985

Kelesidis, T. and Falagas, M. E. (2015). Substandard/counterfeit antimicrobial drugs. Clinical Microbiology Reviews. 28(2): 443464.

Lee, K., Lim, Y. S., Yong, D., Yum, J. H. and Chong, Y. (2003). Evaluation of the Hodge test and the imipenem- EDTA doubledisk synergy test for differentiating metallo- beta- lactamase producing isolates of Pseudomonas spp. and Acinetobacter. spp. J. Clin. Microbiol., 41:4623-4629.

Levashov, E. A. (2014). Overcoming resistance to beta-lactam antibiotics. Svinovodstvo (Moskva), (8), 38-39.

Leverstein-van Hall, M. A., Blok, H. E. M., Donders, A. R. T., Paauw, A., Fluit, A. C., and Verhoef, J. (2003). Multidrug resistance among Enterobacteriaceae is strongly associated with the presence of integrons and is independent of species or isolate origin. The Journal of infectious diseases.187(2): 251-259.

Lucet, J. C., Decré, D., Fichelle, A., Joly-Guillou, M. L., Pernet, M., Deblangy, C., Kosmann, M. J. and Régnier, B. (1999). Control of a prolonged outbreak of extended-spectrum $\beta$-lactamaseproducing Enterobacteriaceae in a university hospital. Clinical infectious diseases, 29(6): 1411-1418.

Lynch III, J. P., Clark, N. M., and Zhanel, G. G. (2013). Evolution of antimicrobial resistance among Enterobacteriaceae (focus on extended spectrum $\beta$-lactamases and carbapenemases). Expert opinion on pharmacotherapy. 14(2): 199-210.

Magiorakos, A. P., Srinivasan, A., Carey, R. B., Carmeli, Y., Falagas, M. E., Giske, C. G., Harbarth, S., Hindler, J. F., Kahlmeter, G., Olsson-Liljequist, B., Paterson, D. L., L. B. Rice, L. B., Stelling, J., Struelens, M. J., Vatopoulos, A., Weber, J. T. and Monnet, D. L. (2012). Multidrug-resistant, extensively drugresistant and pandrug-resistant bacteria: an international expert proposal for interim standard definitions for acquired resistance. Clinical Microbiologyand Infection 18: 268-281.

Mahrouki, S., Chihi, H., Bourouis, A., Ben-Moussa, M., Barguellil, F. and Belhadj, O. (2011). First characterisation in Tunisia of plasmid mediated AmpC bêta-lactamase DHA-1 coexpressed TEM-24 and QnrA6 in a multidrug resistant Proteus mirabilis clinical strain. African Journal of Microbiology Research 5: 3913-3918.

Manyi-Loh, C., Mamphweli, S., Meyer, E., and Okoh, A. (2018). Antibiotic use in agriculture and its consequential resistance in 
environmental sources: potential public health implications. Molecules, 23(4): 795.

Mendonca, N., Joana, L., Vera, M. and Eugenia, F., (2007). The Antimicrobial Resistance Surveillance Program in Portugal, Manuela C. Spread of extended-spectrum beta-lactamase CTX-Mproducing Escherichia coli clinical isolates in community and nosocomial environments in Portugal. Antimicrobial Agents and Chemotherapy, 51: 1946-1955.

Mirza, S., Jadhav, S., Misra, R. N. and Das, N. K. (2019). Coexistence of $\beta$-Lactamases in Community-Acquired Infections in a Tertiary Care Hospital in India. International Journal of Microbiology. 2019: 1-5. Available at: https://oi.org/10.1155/2019/7019578

Nepal, K., Pant, N. D., Neupane, B., Belbase, A., Baidhya, R., Shrestha, R. K., Lekhak, B., Bhatta, D. R. and Jha, B. (2017). Extended spectrum beta-lactamase and metallo beta-lactamase production among Escherichia coli and Klebsiella pneumoniae isolated from different clinical samples in a tertiary care hospital in Kathmandu, Nepal. Annals of clinical microbiology and antimicrobials, 16(1), 62.doi 10.1186/s12941-017-0236-7

Oberoi, L., Singh, N., Sharma, P. and Aggarwal, A. (2013). ESBL, MBL and Ampc $\beta$ lactamases producing superbugs-Havoc in the Intensive Care Units of Punjab India. Journal of clinical and diagnostic research: $J C D R, 7(1), 70$.

Olowe, O. A., Oladipo, G. O., Makanjuola, O. A. and Olaitan, J. O. (2012). Prevalence of extended spectrum beta-lactamases (ESBLs) carrying genes in Klebsiella spp. from clinical samples at Ile-Ife, South Western Nigeria. International Journal of Pharma Medicine and Biological Sciences 1: 2278-5221.

Olowo-okere, A., Abdullahi, M. A., Ladidi, B. K., Suleiman, S., Tanko, N., Ungokore, H. Y., and Aliyu, A. (2019). Emergence of metallo-b-lactamase producing gram-negative bacteria in a hospital with no history of Carbapenem usage in northwest Nigeria. Ife Journal of Science, 21(2), 323-331.

Pitout, J. D. D. and Laupland, K. B. 2008. Extended-spectrum $\beta$ lactamase-producing Enterobacteriaceae: An emerging publichealth concern. Lancet Infect Dis.8:159-166.

Pitout, J. D., Nordmann, P., Laupland, K. B., Poirel, L. (2005). Emergence of Enterobacteriaceae producing extended-spectrum lactamases (ESBLs) in the community. J. Antimicrob. Chemother. 56:52- 59 .

Prestinaci, F., Pezzotti, P. and Pantosti, A. (2015). Antimicrobial resistance: a global multifaceted phenomenon. Pathog Glob Health.109(7):309. doi:10.1179/2047773215Y.0000000030
Rawat, D. and Nair, D. (2010). Extended-spectrum $\beta$-lactamases in Gram negative bacteria. Journal of global infectious diseases.2(3): 263-274.doi: 10.4103/0974-777X.68531.

Shrestha, P., Cooper, B. S., Coast, J., Oppong, R., Thuy N. D. T., Phodha, T., Celhay, O., Guerin, P. J., Wertheim, H. and Lubell, Y.(2018). Enumerating the economic cost of antimicrobial resistance per antibiotic consumed to inform the evaluation of interventions affecting their use. Antimicrob Resist Infect Control.7(98). doi:10.1186/s13756-018-0384-3

Song, W., Kim, J., Bae, I. K., Jeong, S. H., Seo, Y. H., Shin, Jong, H., Jang, S. J., Uh, Y., Shin, Jeong, H., Lee, M-K. and Lee, K. (2011). Chromosome-Encoded AmpC and CTX-M ExtendedSpectrum Beta-Lactamases in Clinical Isolates of Proteus mirabilis from Korea. Antimicrobial Agents and Chemotherapy 55: 1414-1419.

Teklu, D. S., Negeri, A. A., Legese, M. H., Bedada, T. L., Woldemariam, H. K. and Tullu, K. D. (2019). Extended-spectrum beta-lactamase production and multi-drug resistance among Enterobacteriaceae isolated in Addis Ababa, Ethiopia. Antimicrobial Resistance and Infection Control. 8(1): 39. Available at:https://doi.org/10.1186/s13756-019-0488-4

Thanner, S., Drissner, D., and Walsh, F. (2016). Antimicrobial resistance in agriculture. MBio, 7(2), e0222715.doi: $10.1128 /$ mbio.02227-15

Ugwu, M. C., Shariff, M., Nnajide, C. M., Beri, K., Okezie, U. M., Iroha, I. R. and Esimone, C. O. (2020). Phenotypic and Molecular Characterization of $\beta$-Lactamases among Enterobacterial Uropathogens in Southeastern Nigeria. Canadian Journal of Infectious Diseases and Medical Microbiology. 2020: 1-9. Available at: https://doi.org/10.1155/2020/5843904

Worthington, R. J. and Melander, C. (2013). Overcoming resistance to $\beta$-lactam antibiotics. The Journal of organic chemistry.78(9), 4207-4213.

Yadav, K.K., Adhikari, N., Khadka, R., Pant, A.D. and Shah, B. (2015). Multidrug resistant Enterobacteriaceae and extended spectrum $\beta$-lactamase producing Escherichia coli: a cross-sectional study in National Kidney Center, Nepal. Antimicrob Resist Infect Control. 4: 42. https://doi.org/10.1186/s13756-015-0085-0.

(C2020 This is an Open Access article distributed under the terms of the Creative Commons Attribution 4.0 International license viewed via https://creativecommons.org/licenses/by/4.0/ which permits unrestricted use, distribution, and reproduction in any medium, provided the original work is cited 